\title{
Predictive Periodontitis: The Most Promising Salivary Biomarkers for Early Diagnosis of Periodontitis
}

\author{
Carlo Cafiero, Gianrico Spagnuolo*D, Gaetano Marenzi, Ranieri Martuscelli, Michele Colamaio \\ and Stefania Leuci (D)
}

Citation: Cafiero, C.; Spagnuolo, G.; Marenzi, G.; Martuscelli, R.;

Colamaio, M.; Leuci, S. Predictive Periodontitis: The Most Promising Salivary Biomarkers for Early Diagnosis of Periodontitis. J. Clin. Med. 2021, 10, 1488. https://doi.org/ $10.3390 / \mathrm{jcm} 10071488$

Academic Editor: Francisco Mesa

Received: 7 February 2021

Accepted: 30 March 2021

Published: 3 April 2021

Publisher's Note: MDPI stays neutral with regard to jurisdictional claims in published maps and institutional affiliations.

Copyright: (c) 2021 by the authors. Licensee MDPI, Basel, Switzerland. This article is an open access article distributed under the terms and conditions of the Creative Commons Attribution (CC BY) license (https:// creativecommons.org/licenses/by/ $4.0 /)$.
Department of Neurosciences, Reproductive and Odontostomatological Sciences, University of Naples, Federico II, 80131 Naples, Italy; c.cafiero@unina.it (C.C.); gaetano.marenzi@unina.it (G.M.); r.martuscelli@unina.it (R.M.); michele.colamaio@libero.it (M.C.); stefania.leuci@unina.it (S.L.)

* Correspondence: gspagnuo@unina.it

Abstract: The primary cause of tooth loss in the industrialized world is periodontitis, a bacterial anaerobic infection whose pathogenesis is characterized by composite immune response. At present, the diagnose of periodontitis is made by a complete status check of the patient's periodontal health; full-mouth plaque score, full-mouth bleeding score, probing depth, clinical attachment level, bleeding on probing, recessions, mobility, and migration are evaluated in order to provides a clear picture of the periodontal conditions of a single patient. Chair-side diagnostic tests based on whole saliva could be routinely used by periodontists for a very early diagnosis of periodontitis, monitoring, prognosis, and management of periodontal patients by biomarker detection, whose diagnostic validity is related to sensitivity and specificity. Recent paper reviews and meta-analyses have focused on five promising host derived biomarkers as candidate for early diagnosis of periodontitis: MMP-8 (Metalloproteinase-8), MIP-1 $\alpha$ (Macrophage inflammatory protein-1 alpha), IL-1 $\beta$ (Interleukin-1 beta), IL-6 (Interleukin-6), and HB (Hemoglobin), and their combinations. Chair-side Lab-on-a-chip (LOC) technology may soon become an important part of efforts to detect such biomarkers in saliva medium to improve worldwide periodontal health in developed nations as well as in underserved communities and poor countries. Their applications in preventive and predictive medicine is now fundamental, and is aimed at the early detection of risk factors or the presence or evolution of the disease, and in personalized medicine, which aims to identify tailor-made treatments for individual patients. The aim of the present paper is to be informative about host derived periodontal biomarkers and, in particular, we intend to report information about the most important immune response derived biomarkers and Hemoglobin as candidates to be routinely utilized in order to obtain a chair-side early diagnosis of periodontal disease.

Keywords: predictive periodontology; lab-on-a-chip; host-derived diagnostic markers; salivary biomarkers; periodontitis

\section{Introduction}

An amazing evolution in dental research has been recorded in the last few years, revealing the intimate mechanisms at the base of Periodontitis, a genetically linked pathology determined by Gram negative anaerobic infection and characterized by composite immune reactions as a response to bacterial load. At the present time, periodontal diagnosis is made by performing a complete clinical status check of the patient's periodontal health (fullmouth plaque score, full-mouth bleeding score, probing depth, clinical attachment level, bleeding on probing, recessions, mobility, migration) supported by digital photographs and periapical X-rays. At present, the periodontal defense strategy is almost totally reactive because periodontists only make a start when periodontal infection has already begun, determining the damage of periodontal tissues [1]. 
The unique predictive test used by periodontists for routinely checking the stability or progression of periodontitis is "Bleeding on Probing, (BoP)" [2], recorded by inserting a periodonatal probe at the bottom of the gingival sulcus or periodontal pocket (Figure 1).

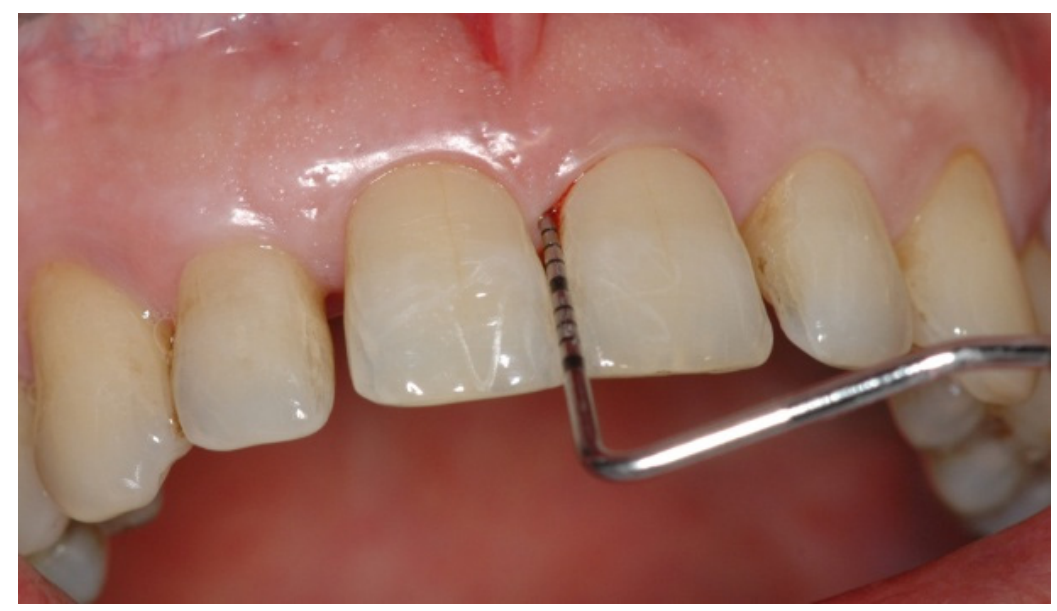

Figure 1. Bleeding on Probing $(\mathrm{BoP})$ : Blood coming out during probing is at this time the unique predictive test used by periodontists.

Blood coming out from the bottom of the pocket can be recorded during probing: BoP that is repeatedly positive $(\mathrm{BoP}+)$ is a predictor of future loss of attachment (activity phase) in $30 \%$ of cases (positive predictive value); meanwhile, BoP repeatedly negative (BoP-) is a predictor of periodontal health in $98 \%$ of cases (negative predictive value) [3-5]. In addition, a functional diagram to evaluate the patient's risk of recurrence of periodontitis ("Spider's

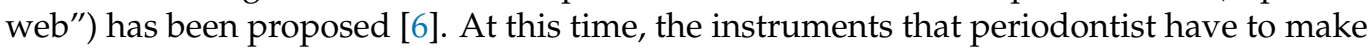
diagnosis of periodontitis are mainly related to a "periodontal reactive approach" because, at this time, we can use very few "periodontal predictive" instruments.

The purpose of a "futuristic" periodontal diagnosis in the near future will be to diagnose periodontal disease before it comes clinically detectable in order to early stop its progression by the use of biomarkers. Biomarkers are biological indicators with high prognostic and predictive value that can be related to the onset or development of a pathology. They must be capable of being measured accurately and quickly and must have a high prognostic or predictive value. In short, they must be able to predict the presence of a disease or its progression, if it is a disease marker, or to give indications on the most appropriate type of drug and response, if it is a treatment response marker. Their applications in preventive and predictive medicine is now fundamental, and is aimed at the early detection of risk factors or the presence or evolution of the disease, and they can also be applied in personalized medicine, which aims to identify tailor-made treatments for individual patients. The aim of the present paper is to be informative to clinicians who are not familiar with the details of periodontal biomarkers; in particular, we intend to report information about the most important host derived biomarkers and among them the immune response derived biomarkers and Hemoglobin as candidates that can be routinely utilized in order to obtain a chair-side early diagnosis of periodontal disease. The most important therapeutic topic is that, by the use of periodontal biomarkers, we could "intercept" periodontal disease at a very early stage, when periodontal tissues lesions are not yet clinically detectable and, as a consequence, we can treat the disease early in order to stop it before periodontal lesions are established.

\section{Immune Response in Periodontitis}

Worldwide periodontists have to make a huge cultural effort in changing the actual "reactive" therapeutic point of view into a futuristic "predictive" one. On account of this, it appears very important (i) to identify a periodontal initial lesion when it is not 
yet clinically detectable and (ii) to intercept the so called "active phase" of periodontitis. In order to get this result, clinicians need hi-tech diagnostic tools in order to detect the specific biomarkers that are released during the early phases of immune response. The host-microbial equilibrium constitutes the situation for clinically healthy periodontal tissue; when plaque bacterial load occurs it determines an important immune response, which releases many substances in periodontal tissues, and some of them could be eligibly as biomarkers for the early diagnosis of Periodontitis.

The most important cells involved in pathogenesis of periodontal diseases are Polymorphonuclear Leukocytes (PMN), Macrophages (Mø), and Osteoclasts [1]. Their functions in periodontal immune response are briefly described below.

In this brief description of the pathogenesis of periodontitis, we focused on the immunological mechanisms and related cells leading to the releasing of molecules eligible as biomarker candidates for an early diagnosis of periodontitis.

\subsection{Polymorphonuclear Leukocytes (PMN) Activation}

PMN leukocytes, representing the first line of defense of periodontal tissues, can cause tissue damage as a result of their accumulation in gingival epithelial tissues. Further tissue damage can be caused by a variety of enzymes and oxygen metabolites that are released by PMN during the immune reaction. The result of these activities is that the junctional epithelium becomes filled with ulcers, allowing the passage of bacteria underneath connective tissue.

Neutrophil collagenase, also known as matrix metalloproteinase-8 (MMP-8) is one of the most representative enzyme involved in the breakdown of the extracellular matrix in Periodontitis. The primary function of MMP-8 is the degradation of type I, II, and III collagens, determining periodontal attachment loss.

\subsection{Macrophage (Mø) Activation}

The second line of defense is mostly represented by macrophages. They play a decisive role in controlling bacterial diffusion in the connective tissue and represent an important source of enzymes, cytokines, and inflammatory mediators such as Interleukin- $1 \beta$ (IL-1 $\beta$ ), Tumor Necrosis Factor- $\alpha$ (TNF- $\alpha$ ), Prostaglandin E2 (PGE2), Transforming Growth Factor- $\beta$ (TGF- $\beta$ ), and Macrophage inflammatory protein-1 alpha (MIP- $1 \alpha /$ CCL3). The primary functions of these molecules are reported below:

- $\quad$ IL-1 $\beta$ is released by LPS-activated macrophages, lymphocytes, and fibroblasts. It stimulates Mø and fibroblasts to secrete PGE2 and causes osteoclastic differentiation and activation [7];

- $\quad$ TNF- $\alpha$ is principally secreted by LPS-stimulated macrophages and lymphocytes and causes osteoclastic differentiation and activation [8];

- $\quad$ PGE2 causes vasodilatation, vasopermeability, and resorption of the alveolar bone;

- IL-1 $\beta$, TNF- $\alpha$ and PGE2 stimulate fibroblasts and Mø to release Metalloproteinases (MMPs), urokinase plasminogen activator (u-PA), tissue inhibitor of metalloproteinases, PGE2, TGF- $\beta$, and interleukin-1 receptor antagonist [9];

- MIP- $1 \alpha$ belongs to the family of chemotactic cytokines [10]. It is secreted by macrophages and performs several functions, such as recruiting inflammatory cells, wound healing, inhibition of stem cells, and activation of bone resorption cells, and it directly induces bone destruction. Cells that secrete MIP- $1 \alpha$ are increased at sites of inflammation and bone resorption. MIP- $1 \alpha$ plays an important role in the pathogenesis of various inflammatory diseases and conditions that exhibit bone resorption, such as periodontitis. Biological fluids from patients with these diseases exhibit elevated levels of MIP- $1 \alpha[11]$.

\subsection{Osteoclast Activation}

Many substances (PGE2, IL-1, IL-6, TNF- $\alpha$ ) secreted by Mø, fibroblasts, plasma cells, and $\mathrm{T}$ lymphocytes are involved in osteoclastic activation. The receptor activator of NF- 
kB ligand (RANKL) promotes osteoclastic differentiation and the inhibition of osteoclast apoptosis. Under physiological conditions, RANKL produced by osteoblasts binds to RANK on the surface of osteoclast precursors. RANKL is up-regulated by Parathyroid hormone $(\mathrm{PTH})$, and IL-1. Osteoprotegerin (OPG) is produced by fibroblasts and constitute a false target for RANK, inhibiting, as a consequence, the osteoclastic activation $[12,13]$ (Figure 2).

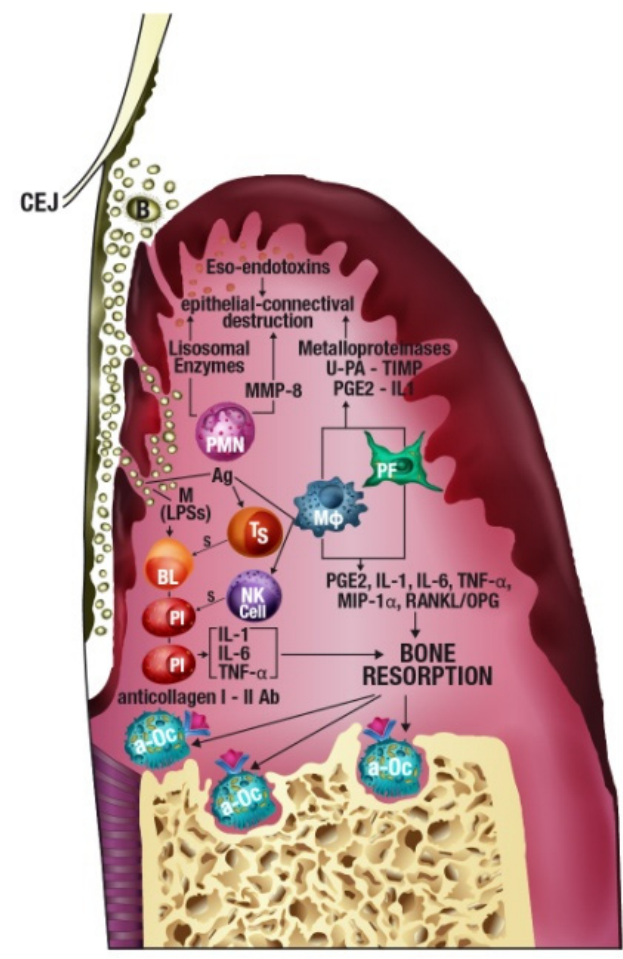

\begin{tabular}{|c|l|}
\hline PO & Bacteria and their \\
releasing products
\end{tabular}

Figure 2. Polymorphonuclear (PMN) leukocytes, representing the first line of defense of periodontal tissues. They release several products during the immune reaction. MMP-8 determines degradation of type I, II, and III collagens.

\section{Immune Response Host Delivered Salivary Products as Biomarkers for Early Periodontal Diagnosis}

The word "biomarker" refers to substances in biologic samples that may predict a disease state in a single patient. Nevertheless, the word has evolved to include genomic or proteomic analyses that could also predict "a response to a drug (efficacy, toxicity, or pharmacokinetics) or indicate an underlying physiologic mechanism" [14].

Many dental associations, such as the American Dental Association (ADA), recognize the importance of scientific research on oral fluid diagnostics [15]. In the near future, the use of a chair-side lab-on-a-chip (LOC) to detect biomarkers for several dental disorders will be desirable in routine dentistry. Industry and research should walk side by side to provide to operators, in a short time, LOC in order to diagnose periodontal disease and other oral diseases at early stages, dealing with extremely small whole saliva volumes in order to detect biomarkers. Oral fluid (whole saliva) includes glandular-duct saliva and gingival crevicular fluid in which many substances derived by the immune response may be detected [16]. Recently, several authors have affirmed that host delivered biomarkers could play a crucial role in the early diagnosis of periodontitis $[17,18]$. In the last few years, several systematic reviews and meta-analyses have focused on the analysis of host derived biomarkers detected in saliva in order to identify among them the most eligible ones for diagnosis of periodontitis $[19,20]$. The diagnostic validity of a single biomarker is related to its sensitivity and specificity. "Sensitivity is the ability to detect a disease in patients in whom the disease is truly present (i.e., a true positive), and specificity is the ability to rule out the disease in patients in whom the disease is truly absent (i.e., a true negative)" [14]. 
Over the last decade, the entire human salivary proteome has been reported on, revealing that 1166 proteins are present in human saliva [21,22], and several have been focused as biomarkers for periodontal diseases [23].

Among them, four clusters of markers released during the immune response may be eligible as biomarkers for periodontitis: (1) host-derived enzymes; (2) tissue breakdown products; (3) host response modifiers [24]; (4) Cytokines.

\subsection{Host-Derived Enzyme}

These are released during the immune response, principally by immunocompetent cells elicited by bacterial load.

\subsubsection{Alkaline Phosphatase}

This is produced by neutrophils, fibroblasts, osteoblasts, osteoclasts, and several bacteria. Its amount appears higher in the active sites than in the inactive ones in the course of periodontitis. Its elevated level in Gingival Crevicular Fluid seems to express early attachment loss [25].

\subsubsection{Beta-Glucuronidase}

This is a lysosomal enzyme whose amount appears higher in active vs. inactive ones [25]. Lamster et al. showed a predictive value of a high level of Beta-glucuronidase in relation to clinical attachment loss [26].

\subsubsection{Cathepsin B}

Cathepsin B is mainly released by macrophages in activity sites; meanwhile, it appears reduced after periodontal treatment [27-30].

\subsubsection{Metalloproteinase-8 (MMP-8, Collagenase-2)}

MMP-8 appears to be the most promising host derived enzyme as a biomarker for the progression of periodontitis vs. stable periodontitis [31,32].

\subsubsection{Metalloproteinase-9 (MMP-9, Gelatinase)}

MMP-9 appears elevated in patients with recurrent attachment loss. Its levels decrease significantly following periodontal therapy [33].

\subsubsection{Dipeptidyl Peptidases II and IV}

These are principally secreted by neutrophils, lymphocytes, macrophages, and fibroblasts.

Their main function lies in the degradation of periodontal collagen tissue. In sites with attachment loss, very high levels of both enzymes were reported [34].

\subsubsection{Metalloproteinase-12 (MMP-12, Elastase)}

This is released from the first line of immune defense, which are neutrophils and macrophages. Higher elastase levels are demonstrated in active sites compared to inactive ones [35-37].

\subsection{Tissue Breakdown Products}

These are released subsequent to the destruction of periodontal tissues, determined directly by bacteria toxins/enzymes, or as a collateral effect of the immune response following bacteria invasion.

3.2.1. Pyridinoline Cross-Linked Carboxyterminal Telopeptide of Type I Collagen (1-CTP)

This represents a molecule derived from collagen tissue degradation, whose detection in gingival crevicular fluid is a biomarker of periodontal disease [38]. 


\subsubsection{Chondroitin-4-Sulphate (C-4-S)}

This is a bone-specific glycosaminoglycan detected in untreated chronic periodontitis sites; a statistically significant correlation between the gingival crevicular fluid (GCF) level of C-4-S, PPD, and CAL has been reported [39].

\subsubsection{Hemoglobin (HB)}

Hemoglobin is a protein localized in red blood cells transporting oxygen to tissues and carbon dioxide from tissues to lungs. $\mathrm{Hb}$ can be revealed in Gingival Crevicular Fluid using salivary occult blood tests (SOBTs). SOBTs have been evaluated as a screening method for periodontal status in order to discriminate subjects with a poor periodontal status [40-51].

\subsection{Host Response Modifiers}

Receptor activaton of the nuclear factor-Kb (RANK)/Osteoprotegerin (OPG)/Receptor activator of nuclear factor-Kb ligand (RANKL) system can be detected in the gingival tissue and whole saliva.

RANK-Expressed by osteoclasts and their precursors-Activated by RANK Ligand binding.

OPG protein is secreted by osteoblasts/bone lining cells-Natural inhibitor of RANK Ligand-Blocks RANK Ligand signaling to balance bone remodeling.

RANKL is secreted by osteoblasts, fibroblasts, bone marrow stromal cells, and activated $\mathrm{T}$ and $\mathrm{B}$ cells [52].

RANKL binds to RANK on the surface of preosteoclasts, activating them in osteoclasts. RANKL is up-regulated by OPG. RANKL is increased whereas OPG is decreased in periodontitis compared to healthy gingiva or gingivitis.

When OPG binds to RANKL, the signal between marrow stromal cells and osteoclast precursors is inhibited; this situation determines a decrease of osteoclastogenesis (Figure 1) [53-55]. The balanced regulation of the RANKL-osteoprotegerin expression system can determine health from disease, as demonstrated in a number of bone destructive diseases, including bacterial arthritis, rheumatoid arthritis [56], periodontitis [57], and, lately, peri-implantitis $[58,59]$.

\subsection{Cytokines}

\subsubsection{Macrophage Inflammatory Protein- $1 \alpha$ (MIP- $1 \alpha)$}

MIP- $1 \alpha$ is a chemotactic cytokine (chemokine). Monocytes, macrophages, activated eosinophils, and fibroblasts are the sources of these proteins $[10,60]$. The main effect of MIP- $1 \alpha$ mainly consists of chemotaxis and transendothelial migration, affecting monocytes, T lymphocytes, dendritic cells, NK cells, and platelets [60].

\subsubsection{Interleukin-1 $\beta$ (IL-1 $\beta$ )}

IL-1 $\beta$ is a pro-inflamatory cytokine expressed particularly by mononuclear phagocytic lineage such as macrophage, NK cells, monocytes, and neutrophils [61,62], but it is also produced by endothelial cells, keratinocytes, synovial cells, osteoblasts, glial cells, and numerous other cells. The main effects of Il-1 $\beta$ are (i) Endothelial cells activation, (ii) Neutrophils diapedesis induction, and (iii) Enhancement of lymphocytes ( $\mathrm{T}$ and $\mathrm{B}$ ) cytokines synthesis $[63,64]$. One of the most important biologic activities of IL-1 is as a lymphocyte activating factor. IL-1 enhances the production of IL-2 T lymphocyte-derived, which determines the increase of B-cellproliferation and in consequent increasing immunoglobulin synthesis. Interaction of IL-1 with the central nervous system is responsible for producing fever. Moreover, IL-1 stimulates bone resorption and collagen deposition [65].

\subsubsection{Interleukin-6 (IL-6)}

This is produced by osteoblastic cells, gingival fibroblasts, gingival lymphocytes, and macrophages stimulated by IL1. It appears as a fundamental factor in the regulation of 
bone remodeling because it acts by increasing bone resorption determined by osteoclasts activated by IL1 [66].

\subsubsection{Tumour Necrosis Factor- $\alpha$ (TNF- $\alpha)$}

TNF $\alpha$ stimulates the proliferation and differentiation of osteoclasts precursors and also acts on mature osteoclasts, activating them $[67,68]$.

\subsubsection{Tumour Necrosis Factor- $\beta$ or Lymphotoxin (TNF- $\beta$ or LT)}

This performs many biological activities similar to those of TNF- $\alpha$, stimulating bone resorption; moreover, it has a negative effect on bone formation, as it inhibits both collagen synthesis and non-collagenic protein synthesis by osteoblasts [67-69].

\subsubsection{Interferon- $\gamma(\mathrm{INF}-\gamma)$}

IFN- $\gamma$ is produced by natural killer (NK) cells as a part of the innate immune response, and by CD4 (Th1, T helper cells) and CD8 cells (Tc, cytotoxic T lymphocyte) as part of specific immune response [70]. IFN- $\gamma$ is also produced by non-cytotoxic innate lymphoid cells (ILC), a family of immune cells first discovered in the early 2010s [71,72]. INF- $\gamma$ is a central factor in the regulation of bone resorption because it can function as a pro- or antiresorptive cytokine [72-75], but the reason why IFN- $\gamma$ has variable effects in bone is unknown.

\section{The Most Promising Host Derived Biomarkers as Candidates for Early Diagnosis of Periodontitis and Their Combination}

At present, well-studied molecules collected in oral fluid (whole saliva) associated with host response factors have been proposed as diagnostic biomarkers for periodontitis [16].

Over 65 components detected in oral fluid have been examined as possible markers for the progression of periodontitis (for a complete review, see [76]).

Among them, five promising biomarkers have been identified as eligible candidates for the diagnosis of periodontitis, and their combination has been evaluated in order to enhance sensibility and specificity of the molecular analysis.

\subsection{Most Promise Biomarkers}

Recent systematic reviews and meta-analyses $[19,20,77]$ have identified five promising host derived biomarkers as good candidates to be elected for the early diagnosis of periodontitis:

- Metalloproteinase-8 (MMP8): An enzyme released by PMN during immune reaction [78]. Salivary and systemic levels of MMP8 appear to be valuable biomarkers for both acute coronary syndrome (ACS) and periodontitis $[79,80]$. Recent reports have shown that local and systemic levels of aMMP-8 can reflect the grading and staging of periodontitis [81,82]. In terms of sensitivity, Arias-Bujanda $\mathrm{N}$ et al. [19] showed a value of $72.5 \%$, according to de Lima et al. [83]. Other authors have reported MMP-8 as one of the strongest markers for tissue destruction, with sensitivity ranging from $65 \%$ to $87 \%$, and specificity ranged from $48 \%$ to $87 \%$ [84,85];

- Macrophage inflammatory protein-1 alpha (MIP-1 $\alpha$ ): Secreted by macrophages increased at the sites of periodontal inflammation and bone resorption [86]. Its increased level can reveal the hidden presence of subclinical inflammation in periodontal clinically healthy sites [87], and it can also discriminate periodontitis in type II diabetics (T2DM) patients. Non-surgical periodontal treatment can affect the salivary level of MIP-1 $\alpha$ [88]. It appears associated with periodontal bone remodeling, showing high sensitivity and specificity of $95 \%$ and $97 \%$, respectively [89];

- Interleukin-1beta (IL-1ß): Released by LPS-activated macrophages (Mø), lymphocytes, and fibroblasts. It stimulates Mø and fibroblasts to secrete PGE2, determining bone destruction [90] and fibroblasts, and Mø releases Metalloproteinases (MMPs), determining connective tissue destruction. Genetic variations of IL-1 $\beta+3954$ appear 
to be associated with increased risk of periodontitis in Koreans (Detection of association between periodontitis and polymorphisms of IL-1beta + 3954 and TNF-alpha -863 in the Korean population after controlling for confounding risk factors) [91]. For IL- $1 \beta$, the sensitivity ranged from $54 \%$ to $88 \%$ and specificity ranged from $52 \%$ to $100 \%$ across five studies $[31,84,85,92,93]$. Clinical parameters showing periodontitis such as gingival index (GI), probing depth (PD), and GCF flow were significantly correlated with gingival crevicular fluid (GCF) and tissue IL-1beta activity [94];

Interleukin-6 (IL-6): A pro-inflammatory cytokine secreted by macrophages in response to specific bacteria and by osteoblaststs to stimulate osteoclastic activity.

- The levels of salivary IL-6 appear to be increased in patients affected by Chronic Periodontitis as compared to healthy controls [95]. Interleukin-6 572C/G and RS1800796 polymorphisms appear as genetic risk factors for periodontitis patients in the Asian population [96,97]. Its sensitivity ranged from $52 \%$ to $80 \%$, and specificity ranged from $48 \%$ to $87 \%$ [31,84,85,93];

- Hemoglobin(HB): This has a sensitivity value of $72 \%$ and a specificity value of $75 \%$ [19]. SOBTs may offer a simple screening method for periodontal status when clinical periodontal examination is not possible, although this test it is not sufficiently specific to be a suitable surrogate for a periodontal clinical examination [48]. Mäkinen et al. [49] reported the presence of hemoglobin ( $\mathrm{Hb})$, detected in the GCF of periodontal disease sites. In addition, Hanioka et al. [50] observed the existence of $\mathrm{Hb}$ in the GCF of mild periodontal pockets. They speculated that invisible bleeding has previously occurred in a pocket with early periodontitis in spite of the negative finding by $\mathrm{BOP}$ inspection (BOP-). This hypothesis was supported by other studies, which suggested that the detection of $\mathrm{Hb}$ derived from microbleeding in gingival sulci may serve as an index for preclinical diagnosis [51,98] (Table 1).

Table 1. Early diagnosis of periodontitis: Sensitivity and Specificity of the most promising host derived biomarkers.

\begin{tabular}{cccc}
\hline Releasing Cells & Biomarker & Sensitivity \% & Specificity \% \\
\hline $\begin{array}{c}\text { Polymorphonuclear } \\
\text { Leukocytes }\end{array}$ & MMP8 (Metalloproteinase-8) & $\begin{array}{c}72 \%[19,79] \\
65.87 \%[80,81]\end{array}$ & $48-87 \%[80,81]$ \\
\hline $\begin{array}{c}\text { Macrophage } \\
\text { inflammatory protein-1 alpha): }\end{array}$ & $95 \%[82]$ & $97 \%[82]$ \\
\hline $\begin{array}{c}\text { Lymphocytes } \\
\text { Fibroblasts }\end{array}$ & IL-1 $\beta$ (Interleukin-1 $\beta)$ & $54-88 \%[31,80,81,83,84]$. & $52-100 \%[31,80,81,83,84]$ \\
\hline $\begin{array}{c}\text { Macrophages } \\
\text { Osteoblaststs }\end{array}$ & IL-6 (Interleukin-6) & $52-80 \%[31,80,81,84]$ & $48-87 \%[31,80,81,84]$ \\
\hline Red Cells & Hemoglobin (HB) & $72 \%[19]$ & $75 \%[19]$ \\
\hline
\end{tabular}

Recently, other proteins have been proposed as promising biomarker of periodontitis:

- Salivary neuropeptides (vasoactive intestinal peptide, VIP and neuropeptide $Y$ NPY) showed significantly higher levels in the saliva of patients with periodontitis and were correlated with bleeding on probing scores in patients with periodontitis [99];

- Oxidative stress-related biomarkers (OS) in saliva and gingival crevicular fluid associated with chronic periodontitis has been reported in a systematic review and meta-analysis. A direct link between CP and OS-related bio- marker levels in the local site has been suggested by a significant decrease of total antioxidant capacity and a significant increase of malondialdehyde (MDA), nitric oxide, total oxidant status (TOS), and 8-hydroxy-de-oxyguanosine levels in the saliva of CP patients [100];

- MicroRNAs (MiRNA-146a and miRNA155) provide consistent, non-invasive, diagnostic and prognostic biomarkers that can be used to monitor periodontal health status in saliva among diabetic and non-diabetic patients [101]; 
- Salivary oxidative stress biomarkers and advanced glycation end products were investigated in a cross-sectional study in patients affected by periodontitis and in periodontally healthy patients with type 2 diabetes and corresponding systemically healthy controls. Salivary 8-hydroxy-2'-deoxyguanosine (8-OHdG) alone, or in combination with 4-hydroxy-2-nonenal (4-HNE), advanced glycation end products (AGE) and AGE receptor (RAGE) for diabetics, and salivary 8-OHdG alone, or in combination with malondialdehyde (MDA) and high sensitivity C-reactive protein (hsCRP) for systemically healthy persons, could potentially serve as non-invasive screening marker(s) of periodontitis [102];

- Soluble Neuropilin-1 (sNRP-1) is a glycoprotein with angiogenic and immune regulatory functions positively related to periodontitis and could probably be involved in the proinflammatory mechanisms observed in periodontal clinical tissue inflammation [103].

\subsection{Combination of Biomarkers for Earliest Diagnosis of Periodontitis}

Many investigators are interested in combining biomarkers to forecast a binary outcome or detect underlying disease [104]. The combination of some of the previously described biomarkers appear to show a very high sensitivity and specificity in order to diagnose periodontitis.

Distinction between gingivitis and periodontitis groups has been analyzed by only one study, which reported sensitivity of $81 \%$ and specificity of $71 \%$ for the combination of IL- 6 and MIP- $1 \alpha$; meanwhile, a combination of IL- $1 \beta$, IL-6, MMP- 8 , and MIP- $1 \alpha$ was found to have a good sensitivity of $78 \%$ and specificity of $78 \%$ [84].

The combination of IL- 6 and MMP-8 showed, for periodontitis vs. healthy gingiva, a high sensitivity of $94 \%$ and a specificity of $100 \%$ [85].

Diagnostic precision was at the maximum for the combination of IL-1 $\beta$, IL-6, and MMP-8, with sensitivity and specificity range of $78-94 \%$ and $77-97 \%$, respectively $[84,85]$.

An outstanding predictive value of $98 \%$ was reported for paired combinatory analysis of IL- $1 \beta$ and MMP- 8 and IL- $1 \beta$ and IL- 6 , as well as the triple combination of IL-6, MMP8 , and IL-1 $\beta$. Finally, an ideal positive predictive value of 100 was calculated for the combination of IL-6 and MMP-8 [85].

\section{Conclusions}

Oral fluid is the mirror of periodontal health. Unfortunately, its importance in the diagnosis of periodontitis as well as of other oral diseases is still underestimated. We think that it is important to underline that, today, dentistry does not appear to be in line with the times in terms of managing biomarkers. The current deficit in the development of new diagnostic strategies is a cultural deficit for which a global strategy is needed in order to favor a modern cultural approach to the diagnosis of oral diseases. In order to fill the cultural gap, it is necessary to update the scientific knowledge of dental operators through a global cultural strategy aimed to involve:

(i) Universities, in teaching predictive dentistry (e.g., the creation of a specific subject in degree courses in dentistry, post-graduate courses, and $\mathrm{PhD}$ courses);

(ii) Dental researchers, in the publication of scientific papers on biomarkers as diagnostic tools for oral diseases;

(iii) Industries, which should provide chair-side LOC to be used by dental operators.

Advances in microfluidics technology are revolutionizing molecular biology procedures for enzymatic analysis, DNA analysis, and proteomics [105]. Digital microfluidics appears promising for future application to diagnose periodontal diseases by the use of a chair-side Lab-on-a-chip technology able to detect the periodontal biomarkers released during the immune response [106-108]. We have to go a long way if we are to change a traditional "reactive" approach to a "predictive" one (Figure 3), but the pathway has already been outlined; it is "time for new guidelines in advanced healthcare" in dentistry [109]. 


\section{PERIODONTITIS}

A change of paradigm:

from a "Reactive" to a "Predictive" clinical approach

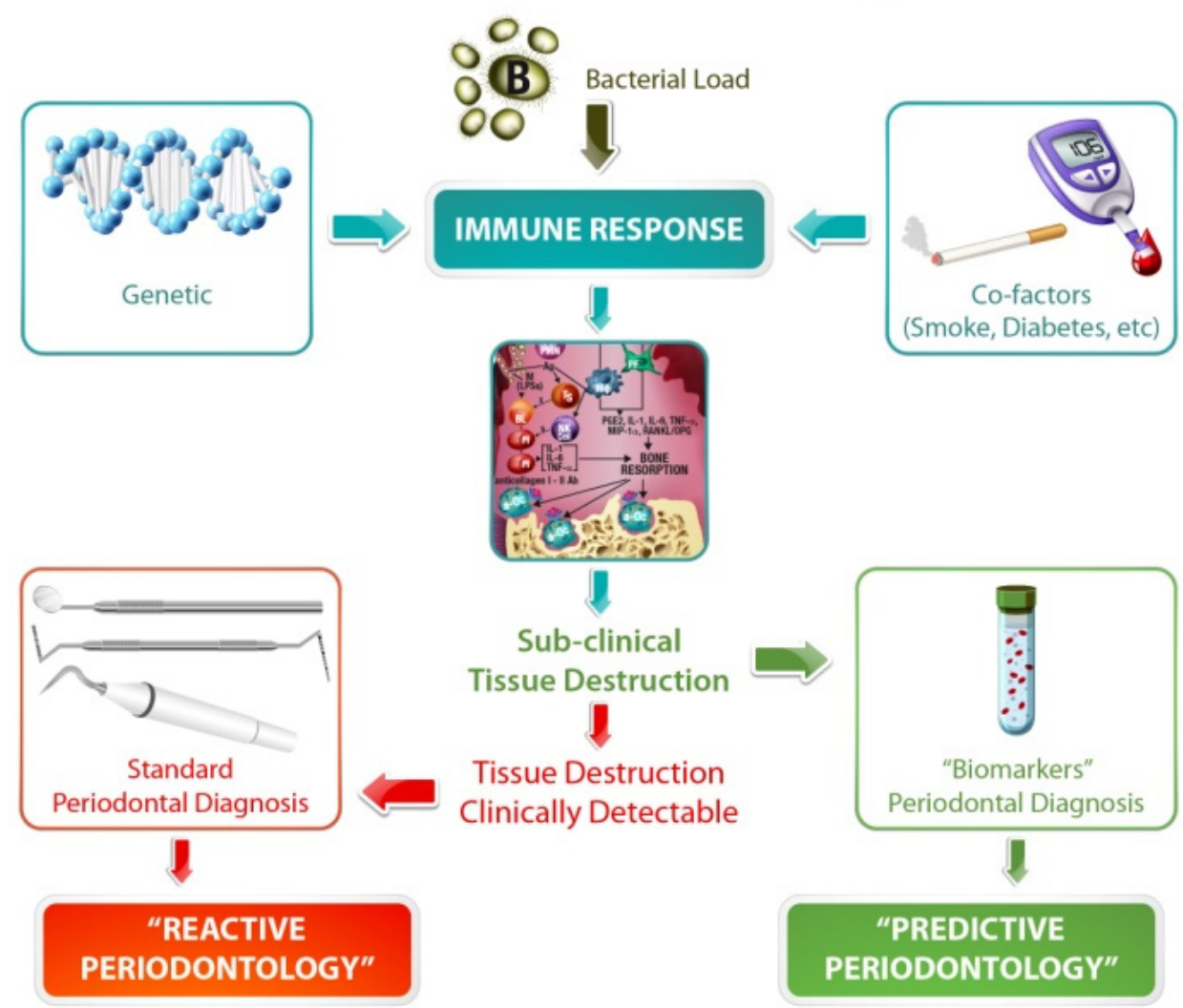

Figure 3. A change of paradigm in periodontal diagnosis is desirable. A shift from a "Reactive" approach, in which clinicians react to the presence of clinically evident periodontal damage, towards a "Predictive" approach, in which the disease is intercepted early when it is already in a sub-clinical phase, is the new objective in periodontal diagnosis.

Author Contributions: Conceptualization, methodology, validation, investigation, C.C., G.M., R.M., M.C.; data curation, C.C., M.C., R.M.; writing-original draft preparation, C.C., M.C., G.M.; writingreview and editing, supervision, C.C., G.S., S.L. All authors have read and agreed to the published version of the manuscript.

Funding: This research received no external funding.

Conflicts of Interest: The authors declare no conflict of interest.

\section{References}

1. Cafiero, C.; Matarasso, S. Predictive, preventive, personalised and participatory periodontology: 'the 5Ps age' has already started. EPMA J. 2013, 4, 16. [CrossRef]

2. Lang, N.P.; Joss, A.; Orsanic, T.; Gusberti, F.A.; Siegrist, B.E. Bleeding on probing. A predictor for the progression of periodontal disease? J. Clin. Periodontol. 1986, 13, 590-596. [CrossRef] [PubMed]

3. Lang, N.P.; Adler, R.; Joss, A.; Nyman, S. Absence of bleeding on probing. An indicator of periodontal stability. J. Clin. Periodontol. 1990, 17, 714-721. [CrossRef] [PubMed]

4. Lang, N.P.; Joss, A.; Tonetti, M.S. Monitoring disease during supportive periodontal treatment by bleeding on probing. Periodontol 2000 1996, 12, 44-48. [CrossRef] [PubMed]

5. Joss, A.; Adler, R.; Lang, N.P. Bleeding on probing. A parameter for monitoring periodontal conditions in clinical practice. J. Clin. Periodontol. 1994, 21, 402-408. [CrossRef] [PubMed]

6. Lang, N.P.; Tonetti, M.S. Periodontal risk assessment (PRA) for patients in supportive periodontal therapy (SPT). Oral Health Prev. Dent. 2003, 1, 7-16. 
7. Dewhirst, F.E.; Ago, J.M.; Peros, W.; Stashenko, P. Bleeding on probing. Synergism between parathyroid hormone and interleukin 1 in stimulating bone resorption in organ culture. J. Bone Miner. Res. 1987, 2, 127-134. [CrossRef] [PubMed]

8. Beutler, B.; Cerami, A. Cachectin and tumour necrosis factor as two sides of the same biological coin. Nature 1986, 320, 584-588. [CrossRef]

9. Cox, S.W.; Eley, B.M. Detection of cathepsin B-and L-, elastase-, tryptase-, trypsin-, and dipeptidyl peptidase IV-like activities in crevicular fluid from gingivitis and periodontitis patients with peptidyl derivatives of 7-amino-4-trifluoromethyl coumarin. J. Periodontal Res. 1989, 24, 353-361. [CrossRef]

10. Zlotnik, A.; Yoshie, O. Chemokines: A new classification system and their role in immunity. Immunity 2000, 12, 121-127. [CrossRef]

11. Bhavsar, I.; Miller, C.S.; Al-Sabbagh, M. Macrophage Inflammatory Protein-1 Alpha (MIP-1 alpha)/CCL3: As a Biomarker. In General Methods in Biomarker Research and their Applications. Biomarkers in Disease: Methods, Discoveries and Applications; Preedy, V., Patel, V., Eds.; Springer: Dordrecht, The Netherlands, 2015. [CrossRef]

12. Hofbauer, L.C.; Khosla, S.; Dunstan, C.R.; Lacey, D.L.; Boyle, W.J.; Riggs, B.L. The roles of osteoprotegerin and osteoprotegerin ligand in the paracrine regulation of bone resorption. J Bone Miner Res. 2000, 15, 2-12. [CrossRef] [PubMed]

13. Yasuda, H.J. Discovery of the RANKL/RANK/OPG system. Bone Miner Metab. 2021, 39, 2-11. [CrossRef] [PubMed]

14. Ray, P.; Le Manach, Y.; Riou, B.; Houle, T.T. Statistical evaluation of a biomarker. Anesthesiology 2010, 112, 1023-1040. [CrossRef] [PubMed]

15. American Dental Association (ADA): Oral Health Topics, Salivary Diagnostics. Available online: https://www.ada.org/en/ member-center/oral-health-topics/salivary-diagnostics (accessed on 15 March 2021).

16. Taba, M., Jr.; Kinney, J.; Kim, A.S.; Giannobile, W.V. Diagnostic biomarkers for oral and periodontal diseases. Dent. Clin. N. Am. 2005, 49, 551-571. [CrossRef] [PubMed]

17. Miller, C.S.; Foley, J.D.; Bailey, A.L.; Campell, C.L.; Humphries, R.L.; Christodoulides, N.; Floriano, P.N.; Simmons, G.; Bhagwandin, B.; Jacobson, J.W.; et al. Current developments in salivary diagnostics. Biomark. Med. 2010, 4, 171-189. [CrossRef]

18. Ghallab, N.A. Diagnostic potential and future directions of biomarkers in gingival crevicular fluid and saliva of periodontal diseases: Review of the current evidence. Arch. Oral. Bio. 2018, 87, 115-124. [CrossRef]

19. Arias-Bujanda, N.; Regueira-Iglesias, A.; Balsa-Castro, C.; Nibali, L.; Donos, N.; Tomás, I. Accuracy of single molecular biomarkers in saliva for the diagnosis of periodontitis: A systematic review and meta-analysis. J. Clin. Periodontol. 2020, 47, 2-18. [CrossRef] [PubMed]

20. Kc, S.; Wang, X.Z.; Gallagher, J.E. Diagnostic sensitivity and specificity of host-derived salivary biomarkers in periodontal disease amongst adults: Systematic review. J. Clin. Periodontol. 2020, 47, 289-308. [CrossRef] [PubMed]

21. Denny, P.; Hagen, F.K.; Hardt, M.; Liao, L.; Yan, W.; Arellanno, M.; Bassilian, S.; Bedi, G.S.; Boontheung, P.; Cociorva, D.; et al. The proteomes of human parotid and submandibular/sublingual gland salivas collected as the ductal secretions. J. Proteome Res. 2008, 7, 1994-2006. [CrossRef] [PubMed]

22. The Human Salivary Proteome Project. Available online: http:/ / www.skb.ucla.edu (accessed on 15 March 2021).

23. Armitage, G.C. Analysis of gingival crevice fluid and risk of progression of periodontitis. Periodontology 2000 2004, 34, 109-119. [CrossRef] [PubMed]

24. Loos, B.G.; Tjoa, S. Host-derived diagnostic markers for periodontitis: Do they exist in gingival crevice fluid? Periodontology 2000 2005, 39, 53-72. [CrossRef] [PubMed]

25. Nakashima, K.; Giannopoulou, C.; Andersen, E.; Roehrich, N.; Brochut, P.; Dubrez, B.; Cimasoni, G. A longitudinal study of various crevicular fluid components as markers of periodontal disease activity. J. Clin. Periodontol. 1996, 23, 832-838. [CrossRef]

26. Lamster, I.B.; Holmes, L.G.; Gross, K.B.; Oshrain, R.L.; Cohen, D.W.; Rose, L.F.; Peters, L.M.; Pope, M.R. The relationship of beta-glucuronidase activity in crevicular fluid to probing attachment loss in patients with adult periodontitis. Findings from a multicenter study. J. Clin. Periodontol. 1995, 22, 36-44. [CrossRef] [PubMed]

27. Kennett, C.N.; Cox, S.W.; Eley, B.M. Investigations into the cellular contribution to host tissue proteases and inhibitors in gingival crevicular fluid. J. Clin. Periodontol. 1997, 24, 424-431. [CrossRef] [PubMed]

28. Eley, B.M.; Cox, S.W. The relationship between gingival crevicular fluid cathepsin B activity and periodontal attachment loss in chronic periodontitis patients: A 2-year longitudinal study. J. Periodontal. Res. 1996, 31, 381-392. [CrossRef] [PubMed]

29. Chen, H.Y.; Cox, S.W.; Eley, B.M. Cathepsin B, alpha2-macroglobulin and cystatin levels in gingival crevicular fluid from chronic periodontitis patients. J. Clin. Periodontol. 1998, 25, 34-41. [CrossRef]

30. Cox, S.W.; Eley, B.M. Cathepsin B/L-, elastase-, tryptase-, trypsin- and dipeptidyl peptidase IV-like activities in gingival crevicular fluid. A comparison of levels before and after basic periodontal treatment of chronic periodontitis patients. J. Clin. Periodontol. 1992, 19, 333-339. [CrossRef]

31. Ramseier, C.A.; Kinney, J.S.; Herr, A.E.; Braun, T.; Sugai, J.V.; Shelburne, C.A.; Rayburn, L.A.; Tran, H.M.; Singh, A.K.; Giannobile, W.V. Identification of pathogen and host-response markers correlated with periodontal disease. J. Periodontol. 2009, 80, 436-446. [CrossRef]

32. Mancini, S.; Romanelli, R.; Laschinger, C.A.; Overall, C.M.; Sodek, J.; McCulloch, C.A. Assessment of a novel screening test for neutrophil collagenase activity in the diagnosis of periodontal diseases. J. Periodontol. 1999, 70, 1292-1302. [CrossRef]

33. Teng, Y.T.; Sodek, J.; McCulloch, C.A. Gingival crevicular fluid gelatinase and its relationship to periodontal disease in human subjects. J. Periodontal. Res. 1992, 27, 544-552. [CrossRef] 
34. Eley, B.M.; Cox, S.W. Correlation between gingival crevicular fluid dipeptidyl peptidase II and IV activity and periodontal at-tachment loss. A 2-year longitudinal study in chronic periodontitis patients. Oral Dis. 1995, 1, 201-213. [CrossRef]

35. Jin, L.; Söder, B.; Corbet, E.F. Interleukin-8 and granulocyte elastase in gingival crevicular fluid in relation to periodontopathogens in untreated adult periodontitis. J. Periodontol. 2000, 71, 929-939. [CrossRef] [PubMed]

36. Smith, Q.T.; Harriman, L.; Au, G.S.; Stoltenberg, J.L.; Osborn, J.B.; Aeppli, D.M.; Fischer, G. Neutrophil elastase in crevicular fluid: Comparison of a middle-aged general population with healthy and periodontitis groups. J. Clin. Periodontol. 1995, 22, 935-941. [CrossRef]

37. Palcanis, K.G.; Larjava, I.K.; Wells, B.R.; Suggs, K.A.; Landis, J.R.; Chadwick, D.E.; Jeffcoat, M.K. Elastase as an indicator of periodontal disease progression. J. Periodontol. 1992, 63, 237-242. [CrossRef] [PubMed]

38. Giannobile, W.V.; Al-Shammari, K.F.; Sarment, D.P. Matrix molecules and growth factors as indicators of periodontal disease activity. Periodontology 2000 2003, 31, 125-134. [CrossRef] [PubMed]

39. Smith, A.J.; Addy, M.; Embery, G. Gingival crevicular fluid glycosaminoglycan levels in patients with chronic adult periodontitis. J. Clin. Periodontol. 1995, 22, 355-361. [CrossRef]

40. Gupta, G. Gingival crevicular fluid as a periodontal diagnostic indicator-I: Host derived enzymes and tissue breakdown products. J. Med. Life. 2012, 5, 390-397. [PubMed]

41. Burt, B.A.; Roder, D.M.; Cecil, J.C.; Eklund, S.A. Saliva-based colorimetric test as an index of gingival inflammation in epidemiologic studies. Community Dent. Oral Epidemiol. 1978, 6, 290-295. [CrossRef] [PubMed]

42. Abbott, B.H.; Caffesse, R.G. The reliability of a colorimetric test in determining gingival inflammation. J. Periodontol. 1978, 49, 564-569. [CrossRef]

43. Takasuka, S.; Nakajima, I.; Sakai, K.; Miyazawa, H.; Miyake, Y.; Akasaka, M. Use of the Salivaster salivary occult blood test for the screening of gingivitis in elementary school children and junior high school students. Shoni Shikagaku Zasshi 1985, 23, 103-110. (In Japanese)

44. Arakawa, H.; Udagawa, E.; Enomoto, K.; Iizuka, Y. An approach to the planning of community health programs for adult periodontal diseases. Screening for periodontal disease using the salivary occult blood test. Kanagawa Shigaku 1986, 20, 503-508. (In Japanese)

45. Kopczyk, R.A.; Graham, R.; Abrams, H.; Kaplan, A.; Matheny, J.; Jasper, S.J. The feasibility and reliability of using a home screening test to detect gingival inflammation. J. Periodontol. 1995, 66, 52-54. [CrossRef]

46. Ohshima, M.; Fujikawa, K.; Kumagai, K.; Idesawa, M.; Ezawa, S.; Ito, K.; Otsuka, K. Evaluation of a novel test paper strip method for detecting occult blood in saliva as a screening test for periodontal disease. J. Jpn. Soc. Periodontol. 2001, 43, 416-423. [CrossRef]

47. Ohshima, M.; Suzuki, K.; Eda, M.; Sato, M.; Ito, K.; Murai, S.; Otsuka, K. An immunological test using anti-human hemoglobin monoclonal antibody for detection of occult blood in saliva-comparison with peroxidase method. J. Jpn. Soc. Periodontol. 1997, 39, 273-280. (In Japanese) [CrossRef]

48. Shimazaki, Y.; Akifusa, S.; Takeshita, T.; Shibata, Y.; Doi, Y.; Hata, J.; Ninomiya, T.; Hirakawa, Y.; Kiyohara, Y.; Yamashita, Y. Effectiveness of the salivary occult blood test as a screening method for periodontal status. J. Periodontol. 2011, 82, 581-587. [CrossRef] [PubMed]

49. Mäkinen, K.K.; Sewón, L.; Mäkinen, P.l. Analysis in gingival crevicular fluid of two oligopeptides derived from human hemoglobin $\beta$-chain. J. Periodontal. Res. 1996, 31, 43-46. [CrossRef] [PubMed]

50. Hanioka, T.; Matsuse, R.; Shigemoto, Y.; Ojima, M.; Shizukuishi, S. Relationship between periodontal disease status and combination of biochemical assays of gingival crevicular fluid. J. Periodontal. Res. 2005, 40, 331-338. [CrossRef]

51. Ito, H.; Numabe, Y.; Hashimoto, S.; Sekino, S.; Murakashi, E.; Ishiguro, H.; Sasaki, D.; Yaegashi, T.; Takai, H.; Mezawa, M.; et al. Correlation Between Gingival Crevicular Fluid Hemoglobin Content and Periodontal Clinical Parameters. Periodontology 2016, 87, 1314-1319. [CrossRef]

52. Boyle, W.J.; Simonet, W.S.; Lacey, D.L. Osteoclast differentiation and activation. Nature 2003, 423, 337-342. [CrossRef] [PubMed]

53. Simonet, W.S.; Lacey, D.L.; Dunstan, C.R.; Kelley, M.; Chang, M.S.; Lüthy, R.; Nguyen, H.Q.; Wooden, S.; Bennett, L.; Boone, T.; et al. Osteoprotegerin: A novel secreted protein involved in the regulation of bone density. Cell 1997, 89, 309-319. [CrossRef]

54. Yasuda, H.; Shima, N.; Nakagawa, N.; Mochizuki, S.I.; Yano, K.; Fujise, N.; Sato, Y.; Goto, M.; Yamaguchi, K.; Kuriyama, M.; et al. Identity of osteoclastogenesis inhibitory factor (OCIF) and osteoprotegerin (OPG): A mechanism by which OPG/OCIF inhibits osteoclastogenesis in vitro. Endocrinology 1998, 139, 1329-1337. [CrossRef] [PubMed]

55. Burgess, T.L.; Qian, Y.; Kaufman, S.; Ring, B.D.; Van, G.; Capparelli, C.; Kelley, M.; Hsu, H.; Boyle, W.J.; Dunstan, C.R.; et al. The ligand for osteoprotegerin (OPGL) directly activates mature osteoclasts. J. Cell Bio. 1999, 145, 527-538. [CrossRef]

56. Udagawa, N.; Kotake, S.; Kamatani, N.; Takahashi, N.; Suda, T. The molecular mechanism of osteoclastogenesis in rheumatoid arthritis. Arthritis Res. 2002, 4, 281-289. [CrossRef] [PubMed]

57. Crotti, T.; Smith, M.D.; Hirsch, R.; Soukoulis, S.; Weedon, H.; Capone, M.; Ahern, M.J.; Haynes, D. Receptor activator NF kB ligand (RANKL) and osteoprotegerin (OPG) protein expression in periodontitis. J. Periodont. Res. 2003, 38, 380-387. [CrossRef]

58. Arikan, F.; Buduneli, N.; Kütükçüler, N. Osteoprotegerin levels in peri-implant crevicular fluid. Clin. Oral Implant. Res. 2008, 19, 283-288. [CrossRef] [PubMed]

59. Monov, G.; Strbac, G.D.; Baron, M.; Kandler, B.; Watzek, G.; Gruber, R. Soluble RANKL in crevicular fluid of dental implants: A pilot study. Clin. Implant. Dent Rela.t Res. 2006, 8, 135-141. [CrossRef] 
60. Menten, P.; Wuyts, A.; Van Damme, J. Macrophage inflammatory protein-1. Cytokine Growth Factor Rev. $2002,13,455-481$. [CrossRef]

61. Dinarello, C.A.; Renfer, L.; Wolff, S.M. Human leukocytic pyrogen: Purification and development of a radioimmunoassay. Proc. Natl. Acad. Sci. USA 1977, 74, 4624-4627. [CrossRef]

62. Dinarello, C.A. Overview of the IL-1 family in innate inflammation and acquired immunity. Immunol. Rev. 2018, $281,8-27$. [CrossRef]

63. Dinarello, C.A. Interleukin-1 and interleukin-1 antagonism. Blood 1991, 77, 1627-1652. [CrossRef]

64. Masola, V.; Carraro, A.; Granata, S.; Signorini, L.; Bellin, G.; Violi, P.; Lupo, A.; Tedeschi, U.; Onisto, M.; Gambaro, G.; et al. In vitro effects of interleukin (IL)-1 beta inhibition on the epithelial-to-mesenchymal transition (EMT) of renal tubular and hepatic stellate cells. J. Transl. Med. 2019, 17, 12. [CrossRef]

65. Rosenwasser, L.J. Biologic activities of IL-1 and its role in human disease. J. Allergy Clin. Immunol. 1998, 102, 344-350. [CrossRef] [PubMed]

66. Czuszak, C.A.; Sutherland, D.E.; Billman, M.A.; Stein, S.H. Prostaglandin E2 potentiates interleukin-1 beta induced interleukin-6 production by human gingival fibroblasts. J. Clin. Periodontol. 1996, 23, 635-640. [CrossRef]

67. Mundy, G.R. Inflammatory mediators and the destruction of bone. J. Periodont. Res. 1991, 26, 213-217. [CrossRef]

68. Mundy, G.R. Mechanisms of osteolytic bone destruction. Bone 1991, 12 (Suppl. 1), S1-S6. [CrossRef]

69. Meghji, S. Bone remodelling. Br. Dent J. 1992, 172, 235-242. [CrossRef] [PubMed]

70. Schoenborn, J.R.; Wilson, C.B. Regulation of interferon-gamma during innate and adaptive immune responses. Adv. Immunol. 2007, 96, 41-101. [CrossRef]

71. Artis, D.; Spits, H. The biology of innate lymphoid cells. Nature. 2015, 517, 293-301. [CrossRef] [PubMed]

72. Fox, S.W.; Chambers, T.J. Interferon-gamma directly inhibits TRANCE-induced osteoclastogenesis. Biochem. Biophys. Res. Commun. 2000, 276, 868-872. [CrossRef]

73. Takayanagi, H.; Ogasawara, K.; Hida, S.; Chiba, T.; Murata, S.; Sato, K.; Takaoka, A.; Yokochi, T.; Oda, H.; Tanaka, K.; et al. T-cell-mediated regulation of osteoclastogenesis by signalling cross-talk between RANKL and IFN-gamma. Nature 2000, 408, 600-605. [CrossRef]

74. Madyastha, P.R.; Yang, S.; Ries, W.L.; Key, L.L., Jr. IFN-gamma enhances osteoclast generation in cultures of peripheral blood from osteopetrotic patients and normalizes superoxide production. J. Interferon Cytokine Res. 2000, 20, 645-652. [CrossRef] [PubMed]

75. Gao, Y.; Grassi, F.; Ryan, M.R.; Terauchi, M.; Page, K.; Yang, X.; Weitzmann, M.N.; Pacifici, R. IFN- $\gamma$ stimulates osteoclast formation and bone loss in vivo via antigen-driven T cell activation. J. Clin. Investig. 2007, 117, 122-132. [CrossRef]

76. Lamster, I.B. Evaluation of components of gingival crevicular fluid as diagnostic tests. Ann. Periodontol. 1997, 2, 123-137. [CrossRef]

77. Barros, S.P.; Williams, R.; Offenbacher, S.; Morelli, T. Gingival crevicular fluid as a source of biomarkers for periodontitis. Periodontology 2000 2016, 70, 53-64. [CrossRef]

78. Zhang, L.; Henson, B.S.; Camargo, P.M.; Wong, D.T. The clinical value of salivary biomarkers for periodontal disease. Periodontology 2000 2009, 51, 25-37. [CrossRef] [PubMed]

79. Lahdentausta, L.S.J.; Paju, S.; Mäntylä., P.; Buhlin, K.; Tervahartiala, T.; Pietiäinen, M.; Alfthan, H.; Nieminen, M.S.; Sinisalo, J.; Sorsa, T.; et al. Saliva and serum biomarkers in periodontitis and coronary artery disease. J. Clin. Periodontol. 2018, 45, 1045-1055 [CrossRef]

80. Buduneli, E.; Mäntylä, P.; Emingil, G.; Tervahartiala, T.; Pussinen, P.; Barış, N.; Akıllı, A.; Atilla, G.; Sorsa, T. Acute myocardial infarction is reflected in salivary matrix metalloproteinase-8 activation level. J. Periodontol. 2011, 82, 716-725. [CrossRef] [PubMed]

81. Sorsa, T.; Alassiri, S.; Grigoriadis, A.; Räisänen, I.T.; Pärnänen, P.; Nwhator, S.O.; Gieselmann, D.R.; Sakellari, D. Active MMP-8 (aMMP-8) as a Grading and Staging Biomarker in the Periodontitis Classification. Diagnostics 2020, 10, 61. [CrossRef] [PubMed]

82. Keles Yucel, Z.P.; Afacan, B.; Emingil, G.; Tervahartiala, T.; Kose, T.; Sorsa, T.J. Local and systemic levels of aMMP-8 in gingivitis and stage 3 grade C periodontitis. J. Periodontal. Res. 2020, 55, 887-894. [CrossRef] [PubMed]

83. De Lima, C.L.; Acevedo, A.C.; Grisi, D.C.; Taba, M.; Guerra, E.; De Luca Canto, G. Host-derived salivary biomarkers in diagnosing periodontal disease: Systematic review and meta-analysis. J. Clin. Periodontol. 2016, 43, 492-502. [CrossRef]

84. Ebersole, J.L.; Nagarajan, R.; Akers, D.; Miller, C.S. Targeted salivary biomarkers for discrimination of periodontal health and disease(s). Front. Cell Infect. Microbiol. 2015, 5, 62. [CrossRef] [PubMed]

85. Ebersole, J.L.; Schuster, J.L.; Stevens, J.; Dawson, D., 3rd; Kryscio, R.J.; Lin, Y.; Miller, C.S. Patterns of salivary analytes provide diagnostic capacity for distinguishing chronic adult periodontitis from health. J. Clin. Immunol. 2013, 33, 271-279. [CrossRef]

86. Nisha, K.J.; Suresh, A.; Anilkumar, A.; Padmanabhan, S. MIP-1alpha and MCP-1 as salivary biomarkers in periodontal disease. Saudi Dent J. 2018, 30, 292-298. [CrossRef] [PubMed]

87. Miranda, T.S.; Figueiredo, N.F.; Figueiredo, L.C.; Silva, H.D.P.D.; Rocha, F.R.G.; Duarte, P.M. Cytokine profiles of healthy and diseased sites in individuals with periodontitis. Arch. Oral Biol. 2020, 120, 104957. [CrossRef]

88. Grande, M.A.; Belstrøm, D.; Damgaard, C.; Holmstrup, P.; Könönen, E.; Gursoy, M.; Gursoy, U.K. Salivary concentrations of macrophage activation-related chemokines are influenced by non-surgical periodontal treatment: A 12-week follow-up study. J. Oral Microbiol. 2019, 12, 1694383. [CrossRef]

89. Al-Sabbagh, M.; Alladah, A.; Lin, Y.; Kryscio, R.J.; Thomas, M.V.; Ebersole, J.L.; Miller, C.S. Bone remodeling-associated salivary biomarker MIP-1 $\alpha$ distinguishes periodontal disease from health. J. Periodontal. Res. 2012, 47, 389-395. [CrossRef] [PubMed] 
90. Cheng, R.; Wu, Z.; Li, M.; Shao, M.; Hu, T. Interleukin-1beta is a potential therapeutic target for periodontitis: A narrative review. Int. J. Oral Sci. 2020, 12, 2. [CrossRef] [PubMed]

91. Kim, H.J.; Kim, E.H.; Park, A.K.; Shin, Y.; Kang, J.; Lim, J.; Bhak, J.; Lee, J.Y.; Kim, B.C.; Joo, J.Y. Detection of association between periodontitis and polymorphisms of IL-1 $\beta+3954$ and TNF- $\alpha-863$ in the Korean population after controlling for confounding risk factors. J. Periodontal Res. 2020, 55, 905-917. [CrossRef] [PubMed]

92. Sánchez, G.A.; Miozza, V.A.; Delgado, A.; \& Busch, L. Salivary IL-1 $\beta$ and PGE2 as biomarkers of periodontal status, before and after periodontal treatment. J. Clin. Periodontol. 2013, 40, 1112-1117. [CrossRef]

93. Wu, Y.C.; Ning, L.; Tu, Y.K.; Huang, C.P.; Huang, N.T.; Chen, Y.F.; Chang, P.C. Salivary biomarker combination prediction model for the diagnosis of periodontitis in a Taiwanese population. J. Formos. Med Assoc. 2018, 117, 841-848. [CrossRef]

94. Liu, C.M.; Hou, L.T.; Wong, M.Y.; Rossomando, E.F. Relationships between clinical parameters, Interleukin 1B and histopathologic findings of gingival tissue in periodontitis patients. Cytokine 1996, 8, 161-167. [CrossRef] [PubMed]

95. Batool, H.; Nadeem, A.; Kashif, M.; Shahzad, F.; Tahir, R.; Afzal, N. Salivary Levels of IL-6 and IL-17 Could Be an Indicator of Disease Severity in Patients with Calculus Associated Chronic Periodontitis. Biomed Res. Int. 2018, 2018, 8531961. [CrossRef]

96. Zhao, B.; Li, X.; Li, R. Genetic Relationship Between IL-6 rs1800796 Polymorphism and Susceptibility to Periodontitis. Immunol. Investig. 2019, 48, 268-282. [CrossRef] [PubMed]

97. Jingjin, L.; Zemin, G.; Xin, M.; Donghong, W.; Jianhua, G.; Jie, Y.; Yonggong, W. Correlation between an interleukin-6-572C/G polymorphism and chronic periodontitis. Int. J. Periodontics Restor. Dent. 2010, 30, 301-305.

98. Ito, H.; Numabe, Y.; Hashimoto, S.; Uehara, S.; Wu, Y.H.; Ogawa, T. Usefulness of hemoglobin examination in gingival crevicular fluid during supportive periodontal therapy to diagnose the pre-symptomatic state in periodontal disease. Clin. Oral Investig. 2021, 25, 487-495. [CrossRef]

99. Haririan, H.; Andrukhov, O.; Böttcher, M.; Pablik, E.; Wimmer, G.; Moritz, A.; Rausch-Fan, X. Salivary neuropeptides, stress, and periodontitis. J. Periodontol. 2018, 89, 9-18. [CrossRef]

100. Chen, M.; Cai, W.; Zhao, S.; Shi, L.; Chen, Y.; Li, X.; Sun, X.; Mao, Y.; He, B.; Hou, Y.; et al. Oxidative stress-related biomarkers in saliva and gingival crevicular fluid associated with chronic periodontitis: A systematic review and meta-analysis. J. Clin. Periodontol. 2019, 46, 608-622. [CrossRef] [PubMed]

101. Al-Rawi, N.H.; Al-Marzooq, F.; Al-Nuaimi, A.S.; Hachim, M.Y.; Hamoudi, R. Salivary microRNA 155, 146a/b and 203: A pilot study for potentially non-invasive diagnostic biomarkers of periodontitis and diabetes mellitus. PLoS ONE 2020, 15, e0237004. [CrossRef]

102. Altıngöz, S.M.; Kurgan, S.; Önder, C.; Serdar, M.A.; Ünlütürk, U.; Uyanık, M.; Başkal, N.; Tatakis, D.N.; Günhan, M. Salivary and serum oxidative stress biomarkers and advanced glycation end products in periodontitis patients with or without diabetes: A cross-sectional study. J. Periodontol. 2020, 5. [CrossRef]

103. Prieto, D.; Maurer, G.; Sáez, M.; Cáceres, F.; Pino-Lagos, K.; Chaparro, A. Soluble Neuropilin-1 in gingival crevicular fluid from periodontitis patients: An exploratory cross-sectional study. J. Oral Bio. Craniofac. Res. 2021, 11, 84-87. [CrossRef]

104. Meisner, A.; Parikh, C.R.; Kerr, K.F. Biomarker combinations for diagnosis and prognosis in multicenter studies: Principles and methods. Stat. Methods Med. Res. 2019, 28, 969-985. [CrossRef] [PubMed]

105. Yager, P.; Edwards, T.; Fu, E.; Helton, K.; Nelson, K.; Tam, M.R.; Weigl, B.H. Microfluidic diagnostic technologies for global public health. Nature 2006, 442, 412-418. [CrossRef] [PubMed]

106. Giannobile, W.V.; Beikler, T.; Kinney, J.S.; Ramseier, C.A.; Morelli, T.; Wong, D.T. Saliva as a diagnostic tool for periodontal disease: Current state and future directions. Periodontology 2000. 2009, 50, 52-64. [CrossRef] [PubMed]

107. Christodoulides, N.; Floriano, P.N.; Miller, C.S.; Ebersole, J.L.; Mohanty, S.; Dharshan, P.; Griffin, M.; Lennart, A.; Ballard, K.L.M.; King, C.P.; et al. Lab-on-a-chip methods for point-of-care measurements of salivary biomarkers of periodontitis. Ann. N. Y. Acad. Sci. 2007, 1098, 411-428. [CrossRef]

108. He, W.; You, M.; Wan, W.; Xu, F.; Li, F.; Li, A. Point-of-Care Periodontitis Testing: Biomarkers, Current Technologies, and Perspectives. Trends Biotechnol. 2018, 36, 1127-1144. [CrossRef] [PubMed]

109. Golubnitschaja, O. Time for new guidelines in advanced healthcare: The mission of The EPMA Journal to promote an integrative view in predictive, preventive and personalized medicine. EPMA J. 2012, 3, 5. [CrossRef] 